\title{
LIBERTAD, AMOR Y SEXUALIDAD EN LA OBRA DE JESÚS ALVIZ
}

\author{
František Dratva
}

\begin{abstract}
The article relates the most important biographic data of the Extremaduran writer Jesús Alviz, analyzing the importance and approach of themes like love, sexuality and liberty on extracts of his works. The analysis is based on the short novel Trébedes and the plays ;Qué más da! and Wallada.

Keywords: Jesús Alviz; Extremaduran Literature; Modern Spanish Literature; Love, Sexuality; Liberty.

Resumen: Tras mencionar los principales datos biográficos del escritor extremeño Jesús Alviz, el presente artículo analiza qué importancia y trato da en sus obras el escritor a los temas del amor, sexualidad y libertad. Para este análisis se ha recurrido a un corpus cerrado: la novela corta Trébedes y los dramas iQué más da! y Wallada.
\end{abstract}

Palabras claves: Jesús Alviz; Literatura extremeña; Literatura española contemporánea; Amor; Sexualidad; Libertad.

Jesús Alviz, tal vez el más original de los escritores extremeños de las últimas décadas del siglo XX (Lama y Sáez Delgado 2003: 159), nació en el año 1946 en la localidad cacereña de Acebo. Tras licenciarse en Filosofía trabajó como profesor de Lengua y Literatura Españolas en varios centros educativos tanto en Extremadura como en Madrid. Notables fueron sus intervenciones en los dos primeros Congresos de Escritores Extremeños (1980 y 1982), en que rechazó el estilo literario que en aquella época dominaba en la comunidad: el realismo social, sumándose en 1982 a los escritores que firmaron el «Manifiesto palmario, horrible, pero necesario, contra el arte rupestre del siglo XX en el Oeste de España» (Cayetano Rosado 1985: 23-27). Jesús Alviz falleció en 1998 en Cáceres debido a las enfermedades asociadas con el sida.

Ya que se dedicó a la narrativa y a la labor dramática a la vez, entre las obras que se llegaron a publicar hay narraciones cortas, novelas y dramas. Debido a que tanto los temas de sus obras como el aspecto formal de los mismos no son nada tradicionales (Viola 2010: 125), no pudo contar con ayuda de editoriales y sus primeras obras -Luego, ahora háblame de China (1977) y He amado a Wagner (Memoria biliosa: anverso) (1978)- fueron publicadas en autoedición. Hay que tener en cuenta que en ello influyó no solo la naturaleza de la creación literaria de Jesús Alviz, sino también el hecho de que en aquella época no había editoriales en Extremadura: la Editora Regional de Extremadura fue fundada en 1984. 
Los temas más recurrentes de la creación literaria de Jesús Alviz están estrechamente relacionados entre sí: la libertad, el amor y la sexualidad. La naturaleza homosexual de Alviz fue uno de los motivos por los que era contrario a la política franquista, la cual criticaba toda relación sexual con fin distinto de la procreación, incluidas las relaciones homosexuales. No obstante, estas no son las únicas relaciones sexuales poco ortodoxas que están reflejadas en las obras del autor acebeño, ya que podemos encontrar tanto relaciones incestuosas, como relaciones fuera del matrimonio o las que mantienen personas de gran diferencia de edad -por mencionar algunas de las más comunes-.

Para poder analizar qué tratamiento da Alviz a la libertad, el amor y la sexualidad en un conjunto cerrado, he elegido la novela corta Trébedes (Reverso de memoria biliosa) y, para mostrar la unidad de la creación literaria del autor, los dramas Wallada (1991) y iQue más da! (1989), la primera parte de Trilogía Light. Ya que Alviz no es un autor muy conocido, introduciré varias citas de sus obras a manera de presentación de este autor extremeño.

El caso de Wallada es muy significativo, porque Alviz aspiraba con esta obra al premio para los dramaturgos de la Comunidad de Extremadura, sin embargo, el tribunal se mostró reticente, sobre todo porque Wallada es una obra de «excesos, en todos los sentidos del término, incluso el escenográfico y actoral» (Torres Nebrera 2008: 102). En la primera escena del acto primero, tiene lugar una emasculación de un sacerdote cristiano, llevada a cabo por un médico musulmán. Tal como dice el autor en la nota explicativa: «La escena exigirá un tiempo lento, mudo, ritual. La sangre es la única protagonista.» (Alviz 1991: 6) No obstante, tras ser rechazado en Extremadura, Alviz presentó el drama

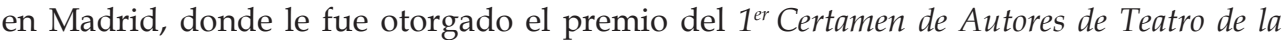
Comunidad de Madrid, confirmándose así un mayor conservadurismo extremeño en comparación con la capital, y no solo en el campo literario.

El amor que juega el papel principal en este drama -ubicado en el siglo XI en el Califato de Córdoba- es el amor homosexual, aunque también aparecen pasajes en que se trata el amor heterosexual. La protagonista es un personaje histórico: Wallada, la hija del penúltimo Califa de Córdoba, al-Mustakfir, poetisa y amante del mayor de los poetas andaluces de aquella época, Ibn Zaydun. Tal como sucede en los dramas de autores homosexuales -siendo yo consciente de que esta división no es políticamente correcta-, Wallada es una mujer fuerte, dominante, con rasgos masculinos (compárense los personajes femeninos de los dramas de Federico García Lorca o Antonio Gala). Esta dominación es patente, por ejemplo, en la segunda escena del primer acto en que Wallada baja a la mazmorra donde había sido castrado el sacerdote cristiano -por orden de la misma-, coge sus órganos sexuales, los desmenuza y con las manos bañadas de sangre proclama: «...de cerca, esto es nada, jnada!» (Alviz 1991: 10).

El elemento heterosexual está representado precisamente por la relación entre Wallada y el poeta Ibn Zaydun. Este está enamorado de la poetisa y está dispuesto a hacer todo para que ella lo ame también. Puesto que el poder y la postura dominante de Wallada depende en parte del hecho de que su padre es califa, Ibn Zayudn llega a afirmar: « $\mathrm{AAh}$, que caiga tu padre! jyo mismo lo asesinaré para que perdiendo el poder vuelva yo a tenerte! ¡Necesito como a la luz a la Wallada de aquellos nobles y dulces gestos primeros!» (Alviz 1991: 17) En la relación de los poetas podemos notar un fenómeno que ya había aparecido en otras obras de Alviz: el hecho de que uno de los amantes pierda el interés por el otro al darse cuenta de que este está enamorado de él. Ibn Zayudn lo expresa de 
esta manera: «Me amaste cuando ignorabas mi sentimiento hacia ti, y ahora que sabes lo mucho que...» (Alviz 1991: 15).

La disposición de Ibn Zaydun a hacer todo por Wallada llega hasta tal punto que se deja castrar para ella, para darle una muestra de su amor. Esto se ve reflejado, junto con los celos que tiene -otra de las constantes de Alviz- en la siguiente intervención: «Wallada, puedo soportarlo todo, jtodo!, tu olvido, tu odio, ;que me hayas castrado!, como dicen por ahí... Y sí, me has castrado, sí... Pero que ¡Ibn Abdus ocupe tu corazón!» (Alviz 1991: 37) La verdad, sin embargo, es diferente: Wallada solo fingió amar a Ibn Abdus para acallar los rumores sobre la impotencia de aquél, está enamorada de la hija del frutero llamada Muhya. Esta busca un amor que sea diferente de los demás, un amor espiritual, sincero, un amor que no esté basado solamente en lo sexual - «Para el amor me es tan indiferente vuestro miembro como vuestro cuerpo» $\mathrm{O}$ «Presiento que ese placer [sexual] me impide gozar más intensamente del amor» (Alviz 1991: 26)-, como lo estuvo en la relación que había tenido con Jallikan, para quien era tan solo una más de una larga sarta de amantes. El lenguaje utilizado en las descripciones de los sentimientos no solo de Muhya «tiene ecos de la mejor poesía arábigo andaluza, rezumante del más fino de los erotismos» (Torres Nebrera 2008:103). La hija del frutero piensa haber encontrado el amor anhelado en Wallada -que desde el principio parece ser la que está más enamorada- sin embargo, todo se estropea en el momento en que la poetisa decide hacer público el amor que siente por Muhya -sin ni siquiera haberlo hablado con ella-, la coge de la mano y se presenta con ella ante los nobles que forman parte de la corte de su padre. Esta falta de respeto, junto con el quizás exagerado empeño que tiene la hija del califa por la relación con Muhya, hacen que esta deje de amarla y llegue a pronunciar: «Creía que era eso [el pene] lo que hacía insufribles a los hombres, pero tú, que no lo tienes, jeres peor que todos ellos!» (Alviz 1991: 57)

Hay paralelismo entre la ostentación que presenta Wallada enamorada de Muhya y la de su padre, enamorado de un tejedor. De la misma manera que su hija -e incluso antes que ella- hace pública la relación con su amante y decide nombrarlo Visir de visires. La escena en que obliga a los nobles a jurarle lealtad a su querido, mostrando ellos una gran reticencia al respecto, recuerda el drama Raquel de otro dramaturgo extremeño: el neoclasicista Vicente García de la Huerta. De la misma manera que en Raquel, los nobles se rebelan, lo que causa el triste fin del amante del Califa: es asesinado.

En Wallada, como ya he mencionado en el caso de Muhya, se trata también la oposición del amor carnal y el amor espiritual. Otro representante del amor espiritual -y quizás por ello dispuesto a la castración- es Ibn Zaydun, como podemos observar en el siguiente diálogo con Jallikan sobre Muhya:

Jallikan: Pues... que para ella los cuerpos no existen..., que anda buscando un amor que la haga olvidarse del mundo..., que...

Ibn Zayudn: Una mujer así merecería ser amada. (Alviz 1991: 28-29)

El tratamiento del sexo en Wallada -aunque es difícil marcar un límite tajante entre el amor y el sexo en la literatura de Jesús Alviz- está en relación con lo que dijo sobre la obra del escritor acebeño Gonzalo Hidalgo Bayal (1997: 64):

...asistimos a la rebelión de un personaje escindido, aprisionado entre sus contradicciones y las barreas externas, sociales. Su obsesión básica, en el sentido noble de la palabra, es erótica, los estrechos cauces morales de la pasión, de la pasión homosexual sobre todo, y a dar testimonio de esta circunstancia se aplica Alviz con furor y con un experimentalismo formal sobreseído. 
El sexo, tal como lo trata en su obra, está estrechamente relacionado con la libertad y sirve para mostrar las limitaciones a las que está sometido el individuo, mientras que la liberación sexual representa la liberación en general, tal como se puede comprobar en la penúltima escena de Wallada, en que los nobles afirman que las mujeres: «ihacen el amor entre ellas!», «Me faltan fuerzas viendo que no se sienten culpables.» $\mathrm{y}$ «iLa culpa de todo la tiene ella! Juró que haría de esa costumbre ley iy se está saliendo con la suya!» (Alviz 1991: 53) Esto está en clara contradicción con las libertades -aunque no sexualesmencionadas en el primer acto: «QQué lejos nuestra tolerancia de otros tiempos!» (Alviz 1991: 6)

¡Qué más da! es un drama que tiene lugar en la contemporaneidad del autor y su relación con Wallada no es patente solo en el hecho de que comparten varios temas, sino también en que el personaje principal, el escritor Diego, se encuentra en una crisis artística, ya que no sabe cómo terminar el drama que está escribiendo; y ese drama es precisamente Wallada. En las primeras intervenciones se narra que Diego se tumba, cierra los ojos y se imagina una escena de Wallada: aparece Muhya en un baño público, confesando a sus amigas que busca otro tipo de amor del que le ofrecen, de la misma manera que en la obra real Wallada, escena tercera del segundo acto. Este momento metaliterario no es nada singular en la obra de Alviz, Hidalgo Bayal lo comenta de la siguiente manera: «... la [literatura] metafictiva, que se piensa a sí misma y, al tiempo de ser la escritura de una aventura, resulta ser la aventura de una escritura.» (Hidalgo Bayal 1997: 240)

Los lazos afectivos expuestos en este drama son mayormente heterosexuales; los sentimientos homosexuales se mencionan también, pero quedan más bien en un segundo plano. La relación principal se desarrolla entre Diego y Araceli, una mujer de treinta años que está locamente enamorada de él. Sin embargo, el escritor la rechaza porque Araceli no le atrae porque es corpulenta, insiste mucho en ser su novia y porque Diego prefiere dedicarse plenamente a la literatura sin tener una relación seria. Encontramos también un triángulo amoroso cuyos vértices están formados por el matrimonio de Emilio y Marga -amigos y vecinos de Diego- y Mercedes, una alumna de Emilio, dado que este es profesor en un instituto.

A pesar de que el personaje principal es Diego, se le da gran importancia a la decadente relación del profesor y su mujer. La crisis matrimonial contrasta con las ilusiones de Araceli, que se hace pasar por la mujer de Diego y no se puede creer que cada uno de los esposos hable mal del otro y que vean la separación como la única solución posible, como podemos observar en el siguiente diálogo entre Araceli y Emilio.

Araceli: ... (Levanta inusualmente la voz.) ¡Tú eres el marido de Marga!

Emilio: Marga es el último punto negro imborrable de mi cabeza, así que no me lo recuerdes a voces precisamente.

Araceli: (Sin bajar el tono). ¿Cómo puede hablar así un esposo de una esposa?

Emilio: ¡Cómo se nota que estás recién casada!

Araceli: (Más alto). ¿Cómo puede hablar así un esposo de una esposa?

Emilio: (A gritos).jPorque estamos hasta el gorro el uno de la otra y viceversa!

Araceli: (Altísimo). ¿Cómo puede hablar así un esposo de una esposa?

Emilio: (Con verdadero estupor, para sí mismo). Me dice alguien que le ocurre así en la vida real iy lo cuelgo! (Alviz 1989: 27-28) 
En la última réplica, Alviz utiliza un recurso metaliterario, haciendo que el personaje de Emilio haga una alusión a que el comportamiento de Araceli es más propio de un drama que de la vida real.

Para dar ejemplo de que Alviz recurre al paralelismo para subrayar la importancia del tema, cito una parte del diálogo entre Araceli y Marga, aturdida por la crisis matrimonial:

Araceli: ... Un deber hecho con amor es un placer, un júbilo, una alegría.

Marga: (Contagiada por la emoción). Me remontas a un pasado mío tan lejano, tan lejano y tan bello... que me cuesta reconocerme en aquella Marga.

Araceli: (Señala su pecho). Aquella Marga sigue ahí... y podrías resucitara.

Marga: Me temo que me encontraría con un cadáver demasiado cadáver... (Alviz 1989: 31)

El tema principal del drama aparece ya en la primera escena en que Muhya -la heroína de Diego y Jesús Alviz a la vez- dice: «Entre ellos [los hombres] y nosotras no hay más que una larga repetición de palabras y gestos vanos.» (Alviz 1989: 10) Los gestos vanos aparecen, por ejemplo, en la fiesta de cumpleaños de Diego, en que Emilio siente un gran deseo de acostarse con Lila, una de las asistentes a la fiesta, y según las palabras de Diego dirigidas a Lila: «...estaba interpretando para atraerte» y en la misma réplica: «Como cualquiera, sabe que lucir delicadeza, aunque sea falsa, ante una mujer, es más rentable que exhibir el sexo en bruto.» (Alviz 1989: 65) Efectivamente, Emilio se embelesa por Lila por lo tanto, ya no se debate solamente entre el deber matrimonial hacia Marga y el amor -o quizás solo atracción sexual- que siente por Mercedes, sino también el fuerte deseo de acostarse con Lila. De esta manera se olvida de que debería cuidar de Mercedes, que había perdido el conocimiento por efecto de alcohol y drogas, y se abalanza sobre Lila, que estaba dispuesta a ayudarle a cuidar de Mercedes. El personaje de Lila lo expresa de esta manera: «Que en vez de atender a su chica medio muerta en el suelo, empezó a meterme mano. ¡Ay que salimiento de hombre! Casi me deja en cueros.» (Alviz 1989: 64) De este modo, el espectador puede comprobar la veracidad de las palabras que Marga pronunció hablando con Araceli:

Mira, el mío ha sido un militante de izquierdas de toda la vida, pero ahora, ante el descafeinamiento que hay, pasa de izquierdas y de todo. ¿Y sabes dónde ha volcado su rabia? ¡En joder! (Araceli salta). Sí, no hay otra obsesión en esa cabeza. Menos conmigo, eso sí, con todo lo que lleve faldas. (Alviz 1989: 32)

La mención del pasado político de Emilio es una de las pocas alusiones a la política en ¡Qué mas da!; siendo la política otro de los temas recurrentes en la obra de Jesús Alviz hay que admitir que en este aspecto es iQué más da! la excepción que confirma la regla.

El elemento homosexual, lo representa otro vecino y amigo de Diego: Joaquín. Este, después de la separación de Diego de su antigua esposa Marisa, pasó cierta época viviendo con el escritor, hasta llegaron a mantener relaciones sexuales. No obstante, lo que para Joaquín era asunto de vida o muerte, para Diego era solo una manera de superar la separación de su mujer. Joaquín pretendió llevar con Diego una relación matrimonial en toda regla, haciendo Alviz de esta manera alusión a algo que podemos encontrar en varias de sus obras: la imposibilidad de los gays de contraer matrimonio no solo durante el franquismo, sino también durante buena parte de la época democrática.

Joaquín es utilizado por Alviz como un representante de un tipo social que el escritor criticaba duramente: homosexual afeminado. Joaquín viste de una manera extravagante 
y no intenta reducir el fuerte amaneramiento por el que está marcado su comportamiento. Representa a la vez a un homosexual que una vez asumida su orientación sexual la hace pública, sin embargo, no es capaz de asumir la crítica que puede aparecer a raíz de su conducta, como podemos observar en el hecho de que se presenta a Araceli como: «Joaquinito, la loca de la casa» (Alviz 1989: 33), sin embargo, después de que Mercedes le llama: «Una maricona histérica.» (Alviz 1989: 62), le pega una bofetada, le escupe en la cara y se va a casa.

La novela corta Trébedes -escrita en 1975 pero publicada en 1982- nos cuenta la historia de J., un mayordomo mudo, en clara referencia a Kafka, que llega a trabajar sucesivamente en las tres plantas de la casa con ricos elementos decorativos opuestos al hierro herrumbroso que muestra el comienzo de la ruina. Esta casa encarna la España franquista. En la primera planta, el protagonista ejerce de mayordomo para una familia adinerada, la representante de la burguesía, posteriormente llega a trabajar en la segunda planta, habitada por miembros de una secta que simboliza la religión y finalmente, consigue trabajo en la tercera planta, donde reside el Supremo y sus súbditos uniformados que cometen todo tipo de delitos contra la humanidad, siendo metáfora del poder político apoyado en el ejército. Rozas Bravo, analizando a los personajes que habitan la casa, que por su parte representan a las mencionadas clases de la sociedad franquista, afirmó que esta «triada maléfica conforma la pirámide causante de la alienación del ser humano» (Rozas Bravo 1995: 236).

El hijo de los señores es un apasionado lector de Nietzsche: J. encuentra en su mesa un libro del filósofo alemán abierto siempre en la misma página, donde se encuentra subrayado el siguiente párrafo -que está en concordancia con las opiniones del autor acebeño-:

Hay que percibir en la Iglesia la mentira, no sólo la falta de verdad: hacer avanzar la Ilustración dentro del pueblo hasta tal punto, que los sacerdotes se vuelvan todos sacerdotes con mala conciencia. (Alviz 1982: 25)

El personaje de la señora está caracterizado tanto por su comportamiento, como por los comentarios de los empleados, la cocinera y la doncella principalmente. Estas la llaman «arpía y locotona» (Alviz 1982: 15, 16), otros apodos le da el mismo autor, por ejemplo: egregia, transmisora de signos que ni le van ni le vienen o la voz núbil toda. Tiene como fetiche una polvera de nácar, de la misma manera que su marido idolatra su fusil máuser. La debilidad intelectual de ella se hace notar en la conversación que mantiene con su marido después de ver una película de monstruos, ya que piensa que se trata de una historia verdadera y que los monstruos son seres reales. Intenta convencer al hijo para que coma -la inapetencia del hijo aparece en varias partes de la novela como muestra de su descontento vital- diciéndole que tiene que ser fuerte por si vienen estos monstruos y atacan a la familia. Tiene que ser su marido el que le explique que se trataba de muñecos hechos de plástico, sin embargo, no parece entenderlo.

El motivo del amor se puede observar en el comportamiento de la doncella del primer piso, que se enamora de J. y expresa su deseo a la cocinera de la siguiente manera: «jestoy tan harta! ¡tan necesitada de que un hombre me amarre para siempre y ser suya, suya, suya!» (Alviz 1982: 13). La cocinera, en alusión a la mudez de J. comenta: «Las palabras sobran para el amor...» (Alviz 1982: 16). Una idea muy parecida aparece en Wallada. No obstante, el amor de la doncella hacia el mayordomo se convierte en odio cuando se ve sorprendida por J. al salir de la habitación del hijo de los señores, tras cohabitar con el 
mismo. Se da cuenta de que si conseguir el amor de J. había sido antes una tarea difícil, ahora se ha vuelto casi imposible; igualmente siente temor a que este la delate ante los señores. En su desesperación decide pedir ayuda del autor, repitiendo el patrón de $\mathrm{Au}$ gusto Pérez:

En su desesperación llega incluso, muy extraliteraria ella, a recurrir a mí, el que suscribe, para que la salve del desastre mediante el matrimonio de ambos, me dice, a través de un artilugio, como sea, me insiste, pero me niego, alegándole que soy un vulgar copista. (Alviz 1982: 32).

Siendo rechazada por el autor decide comunicar a los señores el secreto de J.: este oyó una vez cómo desde el interior de una pared salía una música suave, un canto de sirenas, y obsesionado por esta música está empeñado en descubrir su origen. Cuando fue sorprendido por la doncella con el oído pegado a la pared, la invitó a que escuchara la dulce melodía con él, sin embargo ella no había oído nada, atribuyendo todo esto al buen oído de J. o a su supuesta locura. En el momento en que revela el secreto -lo único que realmente los unía- a la señora, esta, como buena representante de la clase conservadora, se pone histérica y dice a su marido: «Escuchadme, el mayordomo es una amenaza.» (Alviz 1982: 37) Si tenemos en cuenta el hecho de que J. pasaba una parte de su tiempo libre con el oído pegado a la pared -sin tener ningún interés en espiar a los señores-, llegamos a la conclusión de que esta actividad no representaba ninguna amenaza para la familia. Jesús Alviz ha creado una ácida crítica del conservadurismo que teme cualquier desvío de lo «normal».

El tema del sexo se observa tanto en la relación sexual de la doncella con el hijo de los señores -y en la relación paralela que mantiene su padre con la cocinera- como en lo acontecido en la segunda planta: el Jerarca -el representante principal de la secta- se enamora de J. e intenta violarle, manifestándose así la falsedad de la moral que proclama.

En la parte de la novela que trata sobre la estancia de J. en la segunda planta, podemos encontrar esta sátira a la religión católica del rito romano:

$\mathrm{Al}$ igual que en pasadas mitologías, donde una diosa se trocaba un laurel o un toro adoptaba aires de príncipe, muestras del deseo humano de acortar unas distancias que remota y previamente había establecido con sus dioses, con la estricta finalidad de que estos alcanzaran un mayor verismo en su carácter falsamente objetivo y elevado, así también creamos nosotros la nuestra. De esta forma, a nuestra Diosa primigenia le añadimos una Hija, unidas ambas por tan vivo Amor, que de él brotó una tercera Persona, a la que representamos como una Gata de Angora. Aún más, hicimos que su Hija se encarnara, y para ello la introdujimos en el vientre de la Gata, después de unas relaciones castamente amorosas entre ésta y un joven metalúrgico, y que nos naciera luego, no con algo de carácter gatuno, que sería lo mendeliano, sino puramente antropomórfica, o lo que es lo mismo, la redujimos a la domesticidad. (Alviz 1982: 45-46)

Las alusiones que hace el autor mediante la Diosa, la Hija y la Gata de Angora a la Santa Trinidad, representada por el Padre, el Hijo e el Espíritu Santo, son evidentes, de la misma manera que las que relacionan al joven metalúrgico, que intervino en la Inmaculada Concepción, con San José que era carpintero según la fe cristiana. La mención de lo mendeliano es una clara alusión a las contradicciones entre las ciencias y todas las religiones, no solo la católica del rito romano.

Otro elemento paródico es el cordón umbilical, centro de adoración de los miembros de la secta, mediante el cual Alviz hace una crítica de la adoración de las santas reliquias y da fe de su fuerte anticlericalismo, basado en las objeciones de la Iglesia católica respecto a la libertad individual y su relación con el franquismo. 
La estrecha unión que guarda el sexo con la libertad es patente en el discurso del Supremo -el homólogo de Francisco Franco-, al que J. asiste. El Supremo afirma que:

...la verdadera piedra angular de nuestro Mandato es la castración sexual del populacho [la cursiva es mía]. Nadie ignora que el sexo exige revolucionariamente el placer de manera inmediata y constante, pero nuestro cometido ha sido, desde siempre, encauzar esa energía, no de cara a que la plebe satisfaga sus apetitos, sino al trabajo, su trabajo, naturalmente. Para nuestra sobrevivencia en las alturas del Poder nos ha sido, es, y será preciso imbuirles que la satisfacción erótica aquí y ahora es de irracionales y origen del caos y que es conveniente por siempre una postergación y dosificación de la misma, aplazarla precisamente para cuando la citada energía placentera se haya gastado a golpes de explotación laboral, de lo contrario ¿de qué íbamos a vivir nosotros? (Alviz 1982: 84-85)

Es sintomático que tanto la familia burguesa de la primera planta como los «espirituales» de la segunda o los representantes del Poder de la tercera son conscientes de que hay una gran diferencia entre sus palabras y su comportamiento. La familia burguesa celebra ostentosas fiestas a pesar de que ya se están quedando sin dinero, ya que lo importante es dar una buena imagen y hacer todo lo posible para que los otros no sospechen que la verdad pueda diferir de esta imagen. Los representantes de la secta tienen muy claro que lo que proclaman es una impostura, al igual que lo comunican los nuevos miembros durante la ceremonia de la iniciación -una parodia del bautismo-. Y, finalmente, el Supremo pregona que las leyes promulgadas por el Poder no están destinadas a una mejora del país o de la vida de los ciudadanos, sino para que los que participan en este poder puedan llevar una vida placentera: «¿contra qué ley podría atentar Yo, si todas nacieron de mí con el fin de defender mis venalidades, hechas por tanto a mi imagen y semejanza?» (Alviz 1982: 82) Los únicos que se rebelan contra esta farsa son los jóvenes miembros de la secta. Cuando el Supremo se dé cuenta de que hay más rebeldes que antes proclama: «...nada de espirituales sangrando, los quiero muertos.» (Alviz 1982: 89), mientras que el Jerarca está de acuerdo con ello.

No obstante, en el final de la obra hay un cierto aire de optimismo y una esperanza de cambio, ya que después de que J. se diera cuenta de que la música indescifrable es: «la naturaleza en su alegría de vivir, reducida con saña por el Poder a la angostura y estrecheces de unos caños» (Alviz 1982: 90), relaciona las gotas de las lágrimas del hijo de los señores al que habían traído lacerado y maniatado -probablemente por sus pensamientos liberales- con las gotas que caen con cada vez mayor fuerza en el satén de uno de los sillones de la tercera planta: las tuberías se están rompiendo, la libertad está ganando terreno.

Este optimismo desaparece cuando, con ocasión de la publicación de la obra, Alviz pronuncia:

Ingenuo de mí, que creí que por fin la Historia, ese mismo año 75, iba a empezar a ser nuestra compañera de viaje, y que los hechos y la Vida, en su vértigo, iban a desbancar gloriosamente este escrito. (Alviz 1982: contraportada)

Como se ha podido comprobar en las líneas anteriores, Alviz reservó a la libertad un lugar privilegiado en su obra, convirtiéndose este elemento en su tema principal. El concepto de la libertad no quedó limitado al conjunto de las personas con una orientación sexual minoritaria, sino dio lugar a una fuerte crítica del franquismo, acompañada por un rechazo del beatoconservadurismo de la España franquista (Clemente 1998). Alviz, no obstante, recurrió a la sexualidad en su concepto de metáfora de la libertad, demostrando su anhelo por una liberación sexual que sería tan solo una de las consecuencias de una 
liberación general. La sexualidad fue tratada también en relación con el amor, ya que en la creación literaria de Alviz hallamos varias muestras de un deseo sexual desaforado, que propició un fingimiento del sentimiento amoroso. Este, como una de las afecciones más importantes del ser humano, fue analizado por el autor acebeño en distintas formas y desde varios puntos de vista. No obstante, en la mayoría de los casos, Alviz manifestó su actitud pesimista de cara al amor, ya que sus personajes adolecen de inestabilidad, tendencias manipuladoras o un comportamiento condicionado por la incomunicación, tal como lo he pretendido demostrar en este breve análisis.

\title{
Bibliografía
}

Alviz, Jesús (1982), Trébedes (Reverso de memoria biliosa), Madrid: Libertarias.

Alviz, Jesús (1989), iQué más da!, Mérida: Editora Regional de Extremadura.

Alviz, Jesús (1991), Wallada, Madrid: Imprenta de la Comunidad de Madrid.

Hidalgo Bayal, Gonzalo (1997), Equidistancias, Badajoz: Del Oeste Ediciones.

Cayetano Rosado, Moisés (1985), Alquimia: Antología consultada de nuevos y novísimos narradores extremeños, Mérida: Editora Regional de Extremadura.

Clemente, Jeremías (1998), «Jesús Alviz, escritor», El País 11/11/98 [en línea], <http://www.elpais.com/articulo/agenda/EXTREMADURA/Jesus/Alviz/ escritor/elpepigen/19981111elpepiage_1/Tes>, fecha de consulta [20/04/2011].

Gómez García, Manuel (2007), Diccionario Akal de teatro, Madrid: Akal.

Lama, Miguel Ángel - SÁez Delgado, Luis (2009), Literatura en Extremadura, siglo XX: Antología didáctica de textos, Badajoz: Del Oeste Ediciones.

Pecellín Lancharro, Manuel (1997), «Jesús Alviz, Española dicen que es», Actas del VII Congreso de Escritores Extremeños, 123-125.

RozAS BrAVO, José Luis (1995), «Aproximación a la narrativa de Jesús Alviz», Revista de Estudios Extremeños, vol. 51, n. 1, 231-238.

Teijeiro, Miguel Ángel (1984a), «Jesús Alviz, un escritor a la búsqueda del tiempo perdido», Residencia, n. 12, vol. V, 21-23.

TeIJEIro, Miguel Ángel (1984b), «Viaje por la narrativa de Jesús Alviz», Residencia, n. 12, vol. V, 26-31.

TORRES NEBRERA, Gregorio. (2008), «El teatro extremeño en el traspaso de dos siglos», Alborayque 2, 88-123.

Viola, Simón (2008), «La narrativa extremeña en las últimas décadas (1982-2005)», Alborayque 2, 41-87.

Viola, Simón (2010), Literatura en Extremadura 1984-2009, II. Narrativa, Mérida: Editora Regional de Extremadura.

\author{
František Dratva \\ Facultad de Filosofía y Letras \\ Universidad de Extremadura \\ Av. Universidad s/n \\ Cáceres \\ 10071 \\ España \\ dratva1@seznam.cz
}

